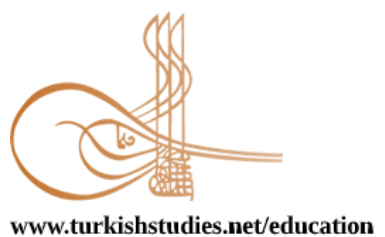

Turkish Studies - Educational Sciences

Research Article / Araştırma Makalesi

\title{
Ortaokul 6. ve 7. Sınıf Öğrencilerinin Doğal Kaynaklara İlişkin Metaforik Algıları
}

\author{
Metaphoric Perceptions of 6th and 7th Grade Secondary School Students Regarding to Natural \\ Resources
}

\author{
Nusret Koca* - Cemal Bilgiç"**
}

\begin{abstract}
Metaphors are expressions that people use to perceive and make sense of the world through their own perspectives. Metaphor can be expressed as a powerful and powerful mental tool that an individual can use to understand and explain a complex, abstract and theoretical phenomenon. By establishing a relationship between two concepts that are not similar to each other through metaphor, a mental schema is reflected in another schema that is not similar to itself. In a class where abstract concepts such as social studies are frequently involved, it is common to use metaphors to make learning tangible and meaningful. For this purpose, various metaphors can be produced in order to have an understanding of the natural resources gains in the 6th class of social studies course, unit 4. Natural resources are spontaneous in nature and the sources of life where mankind has no role in the stages of occurrence. Although there is no human impacts, natural resources are important tool for human beings to meet their basic needs. Considering that natural resources are so important, it is seen that this subject should be given effectively in social studies class. The aim of this study is to reveal the perceptions of the 6th and 7th grade secondary school students towards the concept of "natural resources", and through metaphors. The participants of this research conducted in the phenomenology model consisted of 200 students attending 6th and 7th grades of six public secondary schools in Afyonkarahisar city center, districts and villages in 2017-2018 academic year. The research data was obtained by filling out a form such as "Natural resources are as....., because....." Metaphorical analysis steps and frequency analysis were used in the analysis of data. According to the study findings, $6^{\text {th }}$ and $7^{\text {th }}$ grade students produced 38 metaphors and these metaphors were grouped under 5 categories. The most frequently repeated metaphors of the participants were; stove, ball pen, lamp, light, oven, air conditioning and sunshine. The findings were supported by direct quotations from the sentences they wrote about the reasons for the metaphors of the students. As a result of the research, it was revealed that, generally the participants perceived the concept of natural resources by means of giving heat and light and not being depleted. In addition, the metaphors produced by the students related to the concept of natural resources vary according to the place of the schools they study. In addition, the metaphors produced by the students related to the concept of natural resources vary according to the place of the schools they study. While the students studying in the schools in the city center compare the concept of natural
\end{abstract}

\footnotetext{
* Prof. Dr., Afyon Kocatepe Üniversitesi, Eğitim Fakültesi, Temel Eğitim Bölümü Prof. Dr., Afyon Kocatepe University, Faculty of Education, Primary Education Department ORCID 0000-0002-1415-9683

nkoca@aku.edu.tr

** Doktora Öğrencisi, Afyon Kocatepe Üniversitesi, Sosyal Bilimler Enstitüsü, Türkçe ve Sosyal Bilimler Eğitimi

PhD. Student, Afyon Kocatepe University, The Institute of Social Sciences, Department of Turkish and Social Sciences

Education

ORCID 0000-0002-1111-4180

bilgicemal@hotmail.com

Cite as/ Atıf: Koca, N. \& Bilgiç, C. (2020). Ortaokul 6. ve 7. Sınıf öğrencilerinin doğal kaynaklara ilişkin metaforik algiları. Turkish Studies - Education, 15(3), 1963-1977. https://dx.doi.org/10.29228/TurkishStudies.41934

Received/Geliş: 25 February/Şubat 2020

Accepted/Kabul: 01 June/Haziran 2020

Checked by plagiarism software

Copyright (C) INTAC LTD, Turkey

Published/Yayin: 25 June/Haziran 2020

CC BY-NC 4.0
} 
resources to heating and air conditioning, it is determined that the students studying in schools in the villages and towns compare the concept of natural resources to the stove. Based on this done, it can be concluded that secondary school students were influenced by nearby objects when performing analogy. When the most repeated metaphors are evaluated, it is seen that many of them require high level thinking skills (analysis, synthesis, evaluation).

Structured Abstract: Introduction: Metaphors are expressions that we often refer to in our dialogues, in our perceptions of the world, in our expression of ourselves in the social environment. The word metaphor is derived from the Greek word "Metapherin". While the meta is used to change, pherein means to move. In a class where abstract concepts, such as social studies, are frequently involved, metaphor is common in order for learning to become tangible and meaningful. In a class where abstract concepts such as social studies are frequently involved, it is common to use metaphors to make learning tangible and meaningful. For this purpose, various metaphors can be produced in order to have an understanding of the natural resources gains in the 6th class of social studies course, unit 4 . The aim of this study is to explore the perceptions of the natural resource concept that 6th and 7th grade middle school students have developed in the social studies course in various areas of learning through metaphors. For this purpose, various metaphors can be produced in order to have an understanding of the natural resources gains in the 6th class of social studies course, unit 4.

\section{Purpose of the Study}

The aim of this study is to explore the perceptions of the natural resource concept that 6 th and 7 th grade middle school students have developed in the social studies course in various areas of learning through metaphors. For this purpose, the following questions were sought:

1. By which metaphors do primary school students explain their perceptions of the natural resource concept?

2. In which categories do these metaphors meet in terms of their common characteristics?

\section{Method}

In this study, one of the qualitative research methods, case science (phenomenology) was used. The case focuses on the fact that we are aware of the science pattern but do not have an in-depth and detailed understanding. The case science pattern allows the researcher to better identify judgments, prejudices and assumptions according to other qualitative research patterns. In this context, it is thought that the students of Secondary School will be able to understand their perceptions about the concept of Natural Resources in depth. The participants of this research conducted in the phenomenology model consisted of 200 students attending 6th and 7th grades of five public secondary schools in Afyonkarahisar city center, districts and villages in 20172018 academic year. The sample size depends on what is wanted to be known, the purpose of the researcher, what will be useful, what will be believable, and what can be done with the available time and resources. The schools to be researched and the students to participate in the research were selected within this scope. In this respect, maximum diversity sampling method which is one of the purposive sampling techniques used in the qualitative research tradition has been used. In the convenience sampling method, the aim is to try to find out whether there are any common or shared phenomena between the varied situations and to reveal the different dimensions of the problem according to this diversity (Yıldırım ve Şimşek, 2016: 119). In this research, the maximum diversity method was used in order to see the similarities and differences between the metaphors of the students in the province center, town and village. The application of the research was carried out by the researcher with the permission of the instructor. First of all, students in the study group are informed about the concept of metaphor and application technique. The participants were then asked to complete the statement of " Natural resources are as ......, because ....." in order to reveal the metaphors of the concept of natural resources. Students were asked to express their thoughts by using this expression and focusing only on one metaphor. These metaphors Formed by the students constitute the basic data source of the research. Validity and reliability are the two most important criteria used to ensure the credibility of the research results. Two important processes were carried out to ensure the validity of the research result. (a) The data analysis process is explained in detail(b) As a basic data source, the metaphor images of the students are written in the study and interpretation of the findings. In order to ensure the reliability of the research, expert opinion was applied to confirm whether the metaphor images given under the five conceptual categories in the research represent that conceptual category. At the end of this process, differences of opinion and opinions of the researchers and experts were compared, and the reliability of the research was determined as $94.4 \%$ by using the reliability formula of miles and Huberman (1994). The implementation phase of the study was carried out on 200 students

Turkish Studies - Education, 15(3) 
who were studying in 5 different schools, including provincial center, town and village. Content analysis was used to analyze the data. The main purpose of content analysis is to be able to relate to concepts that can explain the obtained data and in this direction. The data summarized and interpreted in the descriptive analysis are examined in a deeper process in the content analysis and the concepts and themes that are not noticeable in the descriptive analysis can be realized. In other words, the process of content analysis is to gather data that are similar to each other under various concepts and themes and to interpret them in a way that the reader can understand. The analysis process of the collected data was carried out in three stages. Firstly, a temporary list of metaphors produced by students is made in alphabetical order. The relationship between the subject and the source of the metaphor is then examined in detail. The papers were eliminated where the source of the metaphor was not expressed in a healthy way and the reason for the metaphor was not clearly explained. For example, some students presented their personal thoughts about natural resources rather than presenting a metaphor associated with natural resources. Again, although some participants indicated a particular metaphor image, they did not provide any rationale or logical basis for that metaphor. As a result of this elimination, the source was left incomplete and categorized with content analysis on 106 paper, which was excluded from the analysis of 94 paper without justification. In the third stage, metaphors that contain common features are categorized by being subjected to content analysis after the elimination process.

\section{Findings, Conclusion and Recommendations}

38 metaphors produced by middle school students are grouped under 5 categories. The category of 'air conditioning-heating-cooling' category of these categories is highest with $36.28 \%$ (42) and the category of 'continuity of life' has at least a metaphor with $8.62 \%$ (10). According to the findings of the research, secondary school students produced 38 metaphors related to the concept of Natural Resources. The fact that a large number of metaphors have been produced for the concept of natural resources can be considered as an indication that this concept is perceived by students as multidimensional, mixed and abstract. In addition, if it is assumed that metaphors represent only a part of the fact that they are trying to determine, it can be stated that it would be normal to produce a large number of metaphors in the explanation of a very comprehensive concept, such as natural resources. It is observed that the students' viewpoints on natural resources change according to the place of their schools. It was determined that the metaphors they produced related to the concept of natural resources were similar to the assets in their immediate surroundings. Students living in the village and in the town, in the category of air conditioning-heating-cooling, compare the natural resources to the stove, while students studying and living in the city center have produced more air conditioning and heating metaphors in this category. In addition, students classify and perceive natural resources mostly by end-use areas, not by formation characteristics. Social studies teachers, social studies teacher candidates, high school students of various types, school administrators and parents can also be included in the study group.

Keywords: Social Studies, Natural Resources, Metaphor, Aegean Region, Middle School Students.

Öz: Bu araştırmanın amacı, 6. sınıf ve 7. sınıf ortaokul öğrencilerinin sosyal bilgiler dersinde "doğal kaynaklar" kavramına yönelik algılarını metaforlar yoluyla ortaya koymaktır. Olgubilim modelinde gerçekleştirilen bu araştırmanın katılımcılarını 2017-2018 eğitim-öğretim yılında Afyonkarahisar il merkezi, ilçeleri ve köylerinde yer alan altı devlet ortaokulunun 6. ve 7. sınıfına devam etmekte olan 200 öğrenci oluşturmaktadır. Araştırma verileri "Doğal kaynaklar ..... gibidir, çünkü....." formunun doldurulmasıyla elde edilmiştir. Verilerin analizinde metafor analiz basamakları ve frekans analizi kullanılmıştır. Çalışma bulgularına göre ortaokul 6. ve 7. sınıf öğrencileri toplam 38 metafor üretmiş ve bu metaforlar 5 kategori altında toplanmıştır. Katılımcılar tarafından ortaya konulan metaforlardan en fazla tekrar edilenler; soba, tükenmez kalem, lamba, 1şık, firın, klima ve güneş şeklinde sıralanmıştır. Bulgular, öğrencilerin ürettikleri metaforların gerekçelerinden alınan doğrudan alıntılarla desteklenmişlerdir. Araştırma sonucunda katılımcıların genel olarak doğal kaynaklar kavramını 1Sı ve 1şık verme, tükenmeme özelliğiyle algıladıkları ortaya çıkmıştır. Bunun yanı sıra öğrencilerin doğal kaynaklar kavramına ilişkin ürettikleri metaforların, öğrenim gördükleri okulların bulunduğu yerleşim yerine göre değişiklik gösterdiği görülmüştür. İl merkezinde bulunan okullarda öğrenim gören öğrenciler doğal kaynaklar kavramını kalorifer ve klimaya benzetirken, köy ve kasabada bulunan okullarda öğrenim gören öğrenciler doğal kaynaklar kavramını sobaya benzettikleri tespit edilmiştir. Buradan yola çıkarak ortaokul öğrencilerinin benzetme yaparken yakın çevresindeki günlük hayat pratiklerini yansıtan nesnelerden etkilendiği sonucuna ulaşılabilir. 
Anahtar Kelimeler: Sosyal bilgiler, Doğal kaynaklar, Metafor, Ege Bölgesi, Ortaokul Öğrencileri.

\section{Giriş}

Metaforlar insanların dünyayı kendi bakıș açılarıyla algılayıp anlamlandırmasında yararlandıkları ifadelerdir. Metafor kelimesinin kökenine bakılacak olursa, Yunanca dilinden "Metapherin" kelimesinden türediği görülmektedir. Meta kelimesinin anlamı değiştirmek şeklindeyken pherein kelimesinin karşılığı ise taşımaktır (Levine, 2005: 172). Eğitimcilerin çalışmalarına da sık sık konu olan metafor kavramını araştırmacılar kendi bakış açılarına göre açıklama yoluna gitmişlerdir. Morgan (1998: 14) metaforu, "Bir düşünce tarzı ve görme şekli" olarak ifade ederken Lakoff ve Johnson (2005: 25) ise metaforu, "Düşünceye yardımcı olan, insan anlayışını yansıtan fikir aygıtı" olarak belirtmiştir. Metafor kişilerin karşılaştıkları karışık ve soyut bir olguyu açıklarken başvurduğu kuvvetli bir düşünce aygıtıdır (Saban, Koçbeker ve Saban, 2006: 1).

Arslan ve Bayrakçı (2006: 206) ise metaforu bireylerin iç dünyalarını keşfederek tasarlamalarına yönelik kuvvetli bir bilişsel modelleme şeklinde tanımlamıştır. Tanımlamalardan da çıkarılacağı üzere metafor kişinin kavramları kendi zihin dünyası çerçevesinde benzetmeler yoluyla dile getirmesidir. Metafor bu benzetmelerden yola çıkarak bireyin zihnine, kavrayış biçimlerine ve dil yeteneklerine de 1şı tutmaktadır. Metafor aracılığıyla birbiriyle ilişkisi olmayan kavramlar arasında bağlantı kurulur. Bu sayede metaforlar zihindeki spesifik bir anlayış tarzının başka bir bakış açısına evrilmesine neden olur. $\mathrm{Bu}$ sebepten dolayı metafor, düşünsel olarak etkili bir modeldir (Saban, 2008: 424).

Metaforların başlıca özellikleri şu şekilde sıralanabilir (Tompinks ve Lawley, 2002, akt. Kalyoncu, 2012): "Bir kavramı başka bir kavramla açıklama, bir kavramı değişik bir bakış açısıyla yorumlama, bir kavramı farklı bir düşünce kalıbıyla tanımlama." Metafor çalışmaları, kavram ve olgulara ilişkin belirli bir grubun algılarının belirlenmesi amacıyla yapılmasının yanı sıra bireyin zihinsel ve dilsel becerilerinin ortaya konmasına da yardımcı olmaktadır (Tuna ve Budak, 2013). Zira kavramların bilinen önceliği nesneleri sembol olarak temsil etmesidir. Bu birincil özelliğin en büyük faydası az zamanda çok şey söylemek ve düşünme kolaylığı sağlamasıdır (Batur ve Uygun, 2012). Yapılan araştırmalar incelendiğinde, eğitim ve bu alanda bulunan olgu ve kavramların, katılımcı kişiler tarafından nasıl özümsendiği ve ne tür metaforlarla açıklandığı görülmektedir. Metafor çalışması, öğrenmenin önünü açmakta, yaratıcı düşünmeyi desteklemede ve örgütlemede olduğu kadar aynı zamanda eğitimcilerin uyguladığı öğretim yöntemlerini yönlendirmede araç olmaktadır (Kalyoncu, 2012).

Sosyal bilimlerde, kavramlar çok önemli bir yer kaplamaktadır. Düşüncenin doğal döngüsünün açığa çıkmasını sağlar. Olay ve olguların açıklanmasında kavramların belirleyici özelliği de vardır. Öğrencilerin sosyal bilgiler öğretimindeki ilkeleri özümseyebilmesi için kavramlara hâkim olması gerekmektedir. Sosyal bilgiler öğretiminin temel amaçlarından toplumsal sorunlara çözüm bulmak adına kavram öğretimine önem verilmelidir (Uygun ve Batur, 2015). Sosyal bilgiler dersinin müfredatında soyut kavramların çokluğu dikkat çekmektedir. Bu kavramların öğretiminde metafor kullanımının kullanıldığ görülmektedir. Bu doğrultuda 6. sınıf sosyal bilgiler dersi 4. ünitesinde bulunan doğal kaynaklar konusunu kazanımlarının etkili bir şekilde kavratılması amaciyla çeşitli metaforlar üretilebilir.

İnsanoğlunun etkisi olmadan doğada meydana gelmiş olan doğal kaynaklar, insan hayatı için daima yaşamsal öneme sahip olmuştur (Doğanay, 2002). Bu duruma paralel olarak tarihin eski zamanlarından günümüze kadar ülkelerin başlıca rekabet zemini doğal kaynaklar olmuştur. Aynı zamanda doğal kaynaklar ülkelerin gelişmişlik düzeyini gösteren bir numaralı faktördür (Başol, 1991, akt. Uğurlu, 2007). Ülkelerin ekonomik durumuna katkıda bulunması açısından doğal kaynakların değerlendirilmesi önceliklidir. Bu denli önem arz etmesine rağmen doğal kaynakların

Turkish Studies - Education, 15(3) 
bilinçsizce tüketilmesi, gelecek nesillerin bu kaynaklardan kısıtlı faydalanabilmesine neden olabilecektir. $\mathrm{Bu}$ nedenle bireylerin sorumluluklarını bilmeleri ve yerine getirmeleri için gerekli bilgilere sahip olmaları ve bu konunun eğitiminin bireylere etkili bir şekilde verilmesi gerekmektedir (Uğurlu, 2007). Günümüzde bu denli hayati bir önemi bulunan doğal kaynaklar ile ilgili bilincin oluşturulmasında şüphesiz okul kritik rol oynamaktadır. Sosyal Bilgiler Dersi Öğretim Programı'nda doğal kaynaklar kavramı ve öğretimine direkt veya dolaylı olarak sıkça yer verildiği göze çarpmaktadır. Sosyal Bilgiler Dersi Öğretim Programı'nın genel amaçlarının 6. maddesinde; Doğal çevrenin ve kaynakların sınırlılığının farkına varıp çevre duyarlılığı içerisinde doğal kaynakları korumaya çalışmaları ve sürdürülebilir bir çevre anlayışına sahip olmaları şeklinde doğal kaynaklarının önemi yer almaktadır. Sosyal bilgiler becerilerinde ise çevre okuryazarlığı ve harita okuryazarlığı becerileri doğal kaynaklar ile direkt ilişkilendirilebilirken, değişim ve sürekliliği algılama, empati, gözlem, iletişim, empati, iş birliği ve sosyal katılım becerileri dolaylı olarak doğal kaynaklar kavramı ve öğretimi ile ilişkili olduğu söylenilebilir. Bunlara ilaveten 2017 yılında taslak olarak yayınlanan Sosyal Bilgiler Öğretim Programı'nda revize edilen değerleri incelediğimiz zaman, tasarruf, sorumluluk, vatanseverlik ve dayanışma gibi değerlerin de doğal kaynaklar kavramını kapsadığı görülmektedir (Uygun, 2018). Eğitim-öğretim sürecinde ise 5. Öğrenme alanını oluşturan Üretim, Dağıtım ve Tüketim çatısı altında doğal kaynaklar konusuna yer verilmektedir. 5 . Sınıf Sosyal Bilgiler dersinde Üretim, Dağıtım ve Tüketim öğrenme alanında SB.5.5.1. numaralı "Yaşadığı bölgenin ekonomik faaliyetlerini belirler" kazanımı doğrultusunda doğal kaynakların önemi ve korunmasına vurgu vardır. 6. Sınıf sosyal bilgiler dersinde ise aynı ögrenme alanı incelendiğinde, SB.6.5.1. numaral "Ülkemizin kaynaklarıyla ekonomik faaliyetlerini ilişkilendirir." kazanımı ile SB.6.5.2. numaralı, "Kaynakların bilinçsizce tüketilmesinin canlı yaşamına etkilerini analiz eder" kazanımlarında öğrencilere doğal kaynakların önemi ve korunması konusunda bilinç uyandırmak istendiği fark edilmektedir.

Metaforlar, tutum, inanç ve algıların anlamlandırılmasında önemli bir yere sahiptir (Bayram, 2018). Yurt içinde ve yurt dışında son yıllarda metafor kullanımına ilişkin birçok araştırma yapılmıştır. Özellikle Türkiye'de metafor meydana getirme ve metafor aracılığıyla ilgili kavram öğretimi üzerine sık çalışıldığ 1 görülmektedir. Bu araştırmalarda bireylerin kavram ve olgulara karş1 hangi metaforları ne şekilde oluşturdukları, bireylerin benzetme tarzlarını belirlemeye ve yorumlanmaya çalışılmıştır. Literatürde eğitim ortamının önemli iki değişkeni olan öğretmen ve öğrencilere dair davranışların metaforlarla açıklandığı çalışmalara rastlamak mümkündür: (Aktaş ve Uzuner Yurt, 2016; Aydın ve Pehlivan, 2010; Bayram, 2018; Bektaş, Okur ve Karadağ, 2014; Bozpolat, 2015; Ekici, 2016; Kalra ve Bavejab, 2012; Karakuş ve Kozçetin, 2016; Levine,2005; Lin, Shein ve Yang, 2012; Lüle Mert, 2013; Michael ve Malamitsa, 2009; Mouraz, Pereira ve Monteiro, 2013; Shaw, Massengill ve Mahlios, 2008; Tiryaki ve Demir, 2016; Ulusoy, 2013, Yılmaz, Göçen ve Yılmaz, 2013; Zhang, 2016). Yapılan çalışmalara bakıldığında gerek öğretmen ve öğretmen adayları olsun gerekse ilkokul, ortaokul ve ortaöğretim öğrencileri olsun doğal kaynaklar üzerine metafor araştırmaları mevcut olmadığı tespit edilmiştir. Bu bağlamda, yapılan bu araştırmanın literatürde bir boşluğu doldurma iddiası bulunmaktadır. Ortaokul öğrencilerinin doğal kaynaklar kavramı için hangi metaforları oluşturdukları, açıklamaları ile doğal kaynaklar kavramının hangi yönüne vurgu yaptıkları ortaya konmak istenmiştir. Bu araştırmada ortaokul 6. ve 7. sınıf öğrencilerinin doğal kaynaklar kavramına ilişkin algılarını tespit etmek amaçlanmıştır. Araştırmanın bulgularına göre ortaokul öğrencileri doğal kaynaklar kavramına ilişkin 38 metafor üretmiştir. Doğal kaynaklar kavramına ilişkin çok sayıda metafor üretilmiş olması bu kavramın öğrenciler tarafından çok boyutlu, karışık ve soyut olarak algılandığının göstergesi olarak değerlendirilebilir. Ayrıca metaforların belirlemeye çalıştıkları olgunun yalnızca bir parçasını temsil ettikleri varsayılırsa doğal kaynaklar gibi çok kapsamlı bir kavramın açıklanmasında çok sayıda metaforun üretilmesinin normal olacağı belirtilebilir. 


\section{Araştırmanın Amacı}

$\mathrm{Bu}$ araştırmanın amacı, ortaokul 6. sınıf ve 7. sınıf öğrencilerinin sosyal bilgiler dersinde çeşitli öğrenme alanlarında öğrenimlerini gördükleri doğal kaynak kavramına ilişkin geliştirdikleri algıları metaforlar aracılığıyla ortaya çıkarmaktır. Bu genel amaç çerçevesinde aşağıdaki sorulara cevap aranmıştır:

1. Ortaokul öğrencileri, doğal kaynak kavramına ilişkin sahip oldukları algıları hangi metaforlar aracılığı ile açıklamaktadır?

2. Bu metaforlar ortak özellikleri bakımından hangi kategoriler altında toplanmaktadır?

\section{Yöntem}

$\mathrm{Bu}$ çalışmada nitel araştırma yöntemlerinden biri olan olgu bilim (fenomenoloji) kullanılmıştır. Olgu bilim deseni farkında olmamıza rağmen derinlemesine bilgi sahibi olmadığımız olguları araştırmak amacını taşır (Yıldırım ve Şimşek, 2016: 69). Olgu bilim deseni diğer nitel araştırma desenlerine göre araştırmacıya yargıları daha iyi göz önüne serme avantajı sağlar (Finlay, 2008). Bu bağlamda olgu bilim deseniyle ortaokul öğrencilerinin doğal kaynak kavramına yönelik algılarının daha ayrıntılı anlaşılması beklenmektedir.

\section{Çalışma Grubu}

Araştırmanın çalışma grubunu Afyonkarahisar il merkezi, kasabaları ve köylerinde yer alan 5 devlet ortaokulunda 2017-2018 eğitim öğretim yılında öğrenim görmekte olan 6. sinıf ve 7. sınıf toplam 200 öğrenci oluşturmaktadır.

Örneklem büyüklüğü neyin bilinmek istendiğine, araştırmacının amacına, neyin kullanışlı olacağına, neyin inanılır olacağına ve mevcut zaman ve kaynaklar ile neyin yapılabileceğine bağlıdır (Patton, 2014: 244). Araştırma yapılacak okullar ve araştırmaya katılacak öğrenciler bu kapsamda seçilmiştir. Bu doğrultuda nitel araştırma geleneği içinde yer alan amaçlı örnekleme tekniklerinden kolay ulaşılabilir durum örnekleme yöntemi kullanılmıştır. Kolay ulaşılabilir durum örneklemesinin tercih edilmesinin sebebi, araştırmaya pratiklik ve hız kazandırmaktır (Yıldırım ve Şimşek, 2016). Araştırmanın çalışma grubunda yer alan öğrencilerin cinsiyet ve yerleşim yeri değişkenleri Tablo 1 ve Tablo 2'de sunulmuştur.

Tablo 1: Katılımcıların Cinsiyete Göre Dağılımı

\begin{tabular}{ccc}
\hline Cinsiyet & f & \% \\
\hline Kız & 127 & 63 \\
Erkek & 73 & 37 \\
\hline Toplam & $\mathbf{2 0 0}$ & $\mathbf{1 0 0}$
\end{tabular}

Tablo 1 incelendiğinde araştırmaya 127 (\%63) kız, 73 (\%27) erkek olmak üzere toplam 200 öğrenci katıldığı görülmektedir. Cinsiyet dağılımının kız öğrencilerin lehine olduğu görülmektedir.

Tablo 2: Katılımcıların Okullarının Bulunduğu Yerleșim Yerine Göre Dağılımı

\begin{tabular}{ccc}
\hline Öğrenim Gördüğü Yer & f & \% \\
\hline İl Merkezi & 129 & 64 \\
Kasaba & 55 & 27 \\
Köy & 16 & 9 \\
\hline Toplam & $\mathbf{2 0 0}$ & $\mathbf{1 0 0}$ \\
\hline
\end{tabular}


Tablo 2'ye bakıldığında öğrencilerin 129'u (\%64) il merkezinde, 55'i (\%27) kasabada, 16's1 (\%9) ise köyde öğrenim görmektedir. Öğrenim görülen yer dağılımında ise il merkezindeki öğrencilerin sayı olarak fazla olduğu ifade edilebilir. Köy ve kasaba okulundaki şube sayılarının az olması nedeniyle il merkezinde üç farklı okuldaki öğrencilerle çalışılmıştır.

\section{Verilerin Toplanması}

Araştırma Afyonkarahisar il milli eğitim müdürlüğünden araştırmanın yapılması için alınan izin ve etik onay formlarının ardından okul idarecilerinin izni ve öğrencilerin isteği doğrultusunda gerçekleştirilmiştir. Öncelikle çalışma grubunda yer alan öğrencilere metafor kavramı tanıtılmıştır. Ardından uygulama yöntemi ve gidişat hakkında bilgi verilmiştir. Çalışmanın temel hedefi olan katılımcıların metafor kavramına ilişkin algılarını ortaya çıkarmak amacıyla "Doğal kaynaklar ........... gibidir, çünkü ........" ifadesini tamamlamaları istenmiştir. Katılımcıların ortaokul öğrencisi olmaları nedeniyle bilişsel süreçler ayrıntılı bir şekilde açıklanmıştır. Öğrencilerin yalnızca tek bir metafor üzerine yoğunlaşarak düşüncelerini ifade etmeleri istenmiştir. Doğal olarak katılımcıların oluşturdukları bu metaforlar araştırmanın birincil bilgi kaynağını oluşturmaktadır.

\section{Verilerin Analizi}

Verilerin analizinde içerik analizinden yararlanılmıştır. İçerik analizinde temel amaç, elde edilen verileri ayrıntılı bir biçimde açıklayabilmektir. Bu amaçla kavramlara ve söz konusu ilişkilere varabilmektir. İçerik analizinde yapılan işlem, verileri sınıflandırmaktır. Verileri benzerliklerine göre çeșitli kavramlar ve temalar altında bir araya getirmek öncelikli hedeftir. Ardından anlamlı bir şekilde organize ederek yorumlanmaktadır (Yıldırım ve Şimşek, 2016: 242). Toplanılan verilerin analiz süreci beş aşamada gerçekleştirilmiştir:

1. Adlandırma Aşaması: Bu aşamada ortaokul öğrencilerinden toplanan formların tümü toplanarak sıralanmıştır. Ardından katılımcılardan elde edilen formların metafor kısmının boş kalıp kalmadığı veya mantıklı metafor üretilip üretilmediği tespit edilmiştir.

2. Eleme ve Arıtma Așaması: Bu aşamada metafor analizi doğrultusunda her bir metafor ayrıştırılarak benzerlik ve ortaklık açısından gruplandırılmıştır. Metaforun kaynağının açık bir şekilde belirtilmediği ve metaforun gerekçesinin net bir biçimde açıklanmadığı kağıtlar elemeye tabi tutulmuştur. Örneğin bazı öğrenciler doğal kaynaklar ile ilişkili bir metafor imgesi sunmak yerine doğal kaynaklar ile ilgili kişisel düşüncelerini sunmuşlardır. Yine bazı katılımcılar belirli bir metafor imgesi belirtmesine rağmen söz konusu metafora ilişkin herhangi bir gerekçe veya mantıklı dayanak sunmamıştır. Bu eleme sonucunda kaynağı eksik bırakılmış ve gerekçesi sunulmamış 94 kâğı analiz dışında bırakılarak kalan 106 kâğıt üzerinden içerik analizi ile kategorileştirme başlatılmıştır.

3. Kategori Geliştirme Aşaması: Bu aşamada ortaokul öğrencilerinin doğal kaynaklar kavramına yönelik geliştirmiş oldukları metaforlar barındırdıkları ortak özellikler bakımından gruplandırılmıştır. Metafor listesi göz önüne alınarak metaforun kaynağı ve konusu arasındaki ilişki doğrultusunda 5 kavramsal kategori oluşturulmuştur. Duban ve Arısoy (2016), Güveli, İpek, Atasoy ve Güveli (2011), İlter (2015), Ocak ve Gündüz (2006) tarafından yapılan araştırmalarda da metaforların analizinde benzer bir yaklaşım kullanılmıştır.

4. Geçerlik ve Güvenirliği Sağlama Aşaması: Araştırma sonuçlarının inandırıcılığını gerçekleştiren en önemli kriterler geçerlik ve güvenirliktir (Yıldırım ve Şimşek, 2016: 269). Bu doğrultuda iki önemli aşama araştırmanın sonucunun geçerliğini sağlamaya yönelik gerçekleştirilmiştir. (a) Veri analiz süreci açıklanırken ayrıntılı bir yol tercih edilmiştir. (b) Yukarıda bahsedildiği üzere temel veri kaynağı öğrencilerin oluşturduğu metafor imgeleri olmuştur. Bulguların işlenmesinde ve yorumlanmasında bu imgelere yer verilmiştir. Araştırmanın güvenirliğini sağlamak için üç uzman görüşüne başvurulmuştur. İlk olarak ulaşılan 5 kavramsal kategori oluşturulmuştur. İmgelerinin söz konusu bir kavramsal kategoriyi temsil edip etmediği tespit edilmiştir. Uzmanlarla araştırmacının görüş ayrılıkları ve görüş birlikleri karşılaştırılmıştır. Miles ve 
Huberman'ın (1994) güvenirlik formülü kullanılarak araştırmanın güvenirliği \%94,4 olarak tespit edilmiştir.

5. Verileri Bilgisayara Aktarma: Toplam 38 metafor ve 5 kavramsal kategori belirlendikten sonra bütün veriler bilgisayar ortamına aktarılmıştır. Bilgisayara aktarılma işleminin ardından frekans (f) ve yüzde (\%) değerleri hesaplanmıştır.

\section{Bulgular}

Araştırmada çalışmaya katılan ortaokul öğrencilerinin doğal kaynaklara yönelik geliştirdikleri metaforlar ile ilgili elde dilen bulgular Tablo 3'te sunulmuştur.

Tablo 3: Öğrenciler Tarafından Oluşturulan Metaforların Dağılımı

\begin{tabular}{cccccc}
\hline No & Metafor & f & No & Metafor & f \\
\hline 1. & Anne & 3 & 20. & Maden & 1 \\
2. & Avize & 1 & 21. & Manav & 1 \\
3. & Baba & 1 & 22. & Mucize & 2 \\
4. & Bilgi & 1 & 23. & Müzik & 2 \\
5. & Değer & 1 & 24. & Organlar & 1 \\
6. & Doğalgaz & 1 & 25. & Öğretmen & 1 \\
7. & Doktor & 1 & 26. & Ömür & 1 \\
8. & Dolmakalem & 2 & 27. & Pasta & 1 \\
9. & Fener & 2 & 28. & Pizza & 1 \\
10. & Fırın & 8 & 29. & Saç kurutma & 4 \\
11. & Güneş & 7 & 30. & Saklama kabı & 1 \\
12. & Hava & 1 & 31. & Soba & 16 \\
13. & Hayat & 1 & 32. & Su & 1 \\
14. & Hediye & 2 & 33. & Toprak & 1 \\
15. & Isıtıcı & 2 & 34. & Tükenmez kalem & 12 \\
16. & Işık & 9 & 35. & Tüp & 1 \\
17. & Kalorifer & 2 & 36. & Vatan & 1 \\
18. & Klima & 8 & 37. & Yardımcı alet & 1 \\
19. & Lamba & 11 & 38. & Yaşam & 1 \\
\hline
\end{tabular}

Toplam

114

Tablo 3'te ortaokul 6. ve 7. sınıf öğrencilerinin doğal kaynaklara yönelik geliştirdikleri metaforların alfabetik sıraya göre dağılımları görülmektedir. Tabloya göre öğrenciler tarafindan toplanan 38 adet geçerli metafor mevcuttur. 16 adet metafor (soba, tükenmez kalem, lamba, klima, saç kurutma makinesi, müzik, mucize, lamba, klima, 1şık, 1sıtıcı, kalorifer, anne, dolma kalem, fener, firın) birden fazla öğrenci tarafindan üretilmişken 12 adet metafor ise birer öğrenci tarafindan üretilmiştir. Bu bağlamda çalışma grubundaki öğrenciler en çok soba $(\mathrm{n}=16)$, tükenmez kalem $(\mathrm{n}=12)$, lamba $(\mathrm{n}=11)$, ş̧ı $(\mathrm{n}=9)$ ve klima $(\mathrm{n}=8)$, firın $(\mathrm{n}=8)$ metaforlarını ürettikleri görülmektedir. Görüldüğü üzere ortaokul öğrencileri tarafından çok sayıda ve çeşitlikte metafor üretilmiştir. Üretilen metaforların genel anlamda öğrencilerin kendi yaşamlarında karşılaştıkları kavramlar olduğu dikkat çekmektedir. 
Araştırmada elde edilen verilerin analizi sonucunda ortaokul 6. sınıf ve 7. sınıf öğrencilerinin doğal kaynak kavramına dair ürettikleri metaforların kategorileri Tablo 4' te sunulmuştur.

Tablo 4: Öğrenciler Tarafından Oluşturulan Metaforların Ait Oldukları Kategoriler

\begin{tabular}{ccc}
\hline Metafor & f & \% \\
\hline Tükenmeme-yenilenebilir olma & 29 & 25 \\
Işık-Aydınlatma & 23 & 19,82 \\
İklimlendirme-1sıtma-soğutma & 42 & 36,28 \\
Hayatın devamlılı̆̆ & 8 & 8,62 \\
İhtiyaçları karşılama & 12 & 10,34 \\
\hline Toplam & $\mathbf{1 1 4}$ & $\mathbf{1 0 0}$ \\
\hline
\end{tabular}

Tablo 4 incelendiğinde ortaokul öğrencileri tarafindan üretilen 38 metaforun toplam 5 kavramsal kategori altında toplandığı görülmektedir. Bu kategorilerden "İklimlendirme-1sıtmasoğutma" kategorisi \%36,28 (42) ile en yüksek, "Hayatın devamlılığı" kategorisi \%8,62 (10) ile en az metafora sahiptir. Tablo 4'de ortaya konulan her bir kategori ve bunlara ilişkin metafor alt kategorileri aşağıda ele alınmıştır. Öğrenciler tarafindan oluşturulan metaforlar kategori zemininde incelendiğinde, ortaya çıkan kategorilerin öğrencilerin günlük yaşamda karşılaştıkları varlıklar ve nesneler üzerinden temel ihtiyaçlarını karşılayan ögeleri barındırdığ 1 görülmektedir. Bu durum, katılımcıların günlük yaşam pratiklerini farklı şekilde yansıtmaya çalıştıklarının bir göstergesi olarak değerlendirilebilir.

Doğal kaynakları tükenmeme-yenilenebilir olma olarak tanımlayan öğrencilerin oluşturdukları metafor alt kategorileri Tablo 5'te sunulmuştur.

Tablo 5: Tükenmeme-Yenilenebilir Olma

\begin{tabular}{ccc}
\hline Metafor & $\mathbf{f}$ & $\mathbf{\%}$ \\
\hline Güneş & 7 & 29,13 \\
Tükenmez kalem & 12 & 41,37 \\
Dolma kalem & 2 & 6,89 \\
Su & 1 & 3,44 \\
Toprak & 1 & 3,44 \\
Maden & 1 & 3,44 \\
Vatan & 1 & 3,44 \\
Hava & 1 & 3,44 \\
Müzik & 2 & 6,89 \\
Bilgi & 1 & 3,44 \\
\hline Toplam & $\mathbf{2 9}$ & $\mathbf{1 0 0}$
\end{tabular}

Tablo 5 incelendiğinde, araştırmanın katılımcılarının 29'unun (\%25) doğal kaynaklara ilişkin metaforlarının, "Tükenmeme-yenilenebilir olma" kategorisinde toplandığı belirlenmiştir.

Yine Tablo 5'te bunlardan "Tükenmez kalem" (\%41,37), "Güneş" (\%29,13), "Dolma kalem" $(\% 6,89)$ ve "Müzik" $(\% 6,89)$ göze çarpan metaforlar olarak değerlendirilmiştir. En yüksek ikinci orana sahip bu kategoride öğrenciler doğal kaynakları sonu olmayan bir kavram olarak görmektedirler. Öğrencilerin zihinlerindeki sonsuzluk kaynağını belirtme biçimleri kendi hayal güçlerinin çeşitliliğini gözler önüne sermektedir. Tükenmeme-bitmeme kavramlarının vatan, bilgi ve 
müzik gibi farklı bakış açılarıyla değerlendirildiği görülmektedir. Bu kategorideki metaforlar ile, bu değerlendirmeleri destekleyen bazı öğrenci görüşleri şu şekildedir:

"Doğal kaynaklar dolma kalem gibidir çünkü mürekkebi hiç bitmez. Aynı güneş, yıldız, ay, şelale gibidir."

"Doğal kaynaklar tükenmez kalem gibidir çünkü biz onları kullanmak için sürekli sivriltmek zorundayız. Ve biz sivrilttikçe o kalem biter ama bitmeyen kalem olduğu için sürekli kullanılır. Doğal kaynaklardan da sürekli yararlanırız."

"Doğal kaynaklar güneşs gibidir çünkü her gün tekrar çıkar. Doğal kaynaklar da hiçbir zaman bizi birakmaz."

"Doğal kaynaklar müzik gibidir çünkü müzik söyleme özgürlüğümüzün sinırl yoktur. Doğal kaynakların da sinırl yoktur bence"

"Doğal kaynaklar bilgi gibidir çünkü bilgiye ulaşmanın sonu yoktur. İsteyen herkes bilgiye ulaşabilir. Doğal kaynaklar da sonu olmayan kaynaklardır."

Tablo 6: Ișık-Aydınlatma

\begin{tabular}{ccc}
\hline Metafor & $\mathbf{f}$ & \% \\
\hline Fener & 2 & 8,69 \\
Lamba & 11 & 47,82 \\
Avize & 1 & 4,34 \\
Iş1k & 9 & 39,13 \\
\hline Toplam & $\mathbf{2 3}$ & $\mathbf{1 0 0}$ \\
\hline
\end{tabular}

Tablo 6 incelendiğinde, araştırmanın çalışma grubunda yer alan öğrencilerin 23'ünün $(\% 19,82)$ doğal kaynaklara ilişkin metaforlarının, "Işık-aydınlatma" kategorisinde toplandığ görülmektedir.

Bu kategori altındaki metaforlar başlıca, "Lamba" (\%47,82), "Işık" (\%39,13), "Fener" $(\% 8,69)$ ve "Avize" $(\% 4,34)$ şeklinde sıralanmıştır. Bu kategori bağlamındaki metaforlara bakılacak olursa öğrencilerin doğal kaynaklar kavramını sadece aydınlatma perspektifiyle değerlendirdiği görülmektedir. Bu değerlendirmeyi destekleyen bazı öğrenci görüşleri şu şekildedir:

"Doğal kaynaklar bir lambaya benzer çünkü sonsuz bir ışık kaynağıdır ve bizi aydınlatır."

"Doğal kaynaklar ampule benzer. Ampul aydınlatır. Güneş de bizim etrafimızı aydınlatır."

Tablo 7: İklimlendirme-Isıtma-Soğutma

\begin{tabular}{ccc}
\hline Metafor & $\mathbf{f}$ & \% \\
\hline Firın & 8 & 19,04 \\
Soba & 16 & 38,09 \\
Isıtıcı & 2 & 4,76 \\
Kalorifer & 2 & 4,76 \\
Saç kurutma & 4 & 9,52 \\
makinesi & 8 & 19,04 \\
Klima & 1 & 2,38 \\
Tüp & 1 & 2,38 \\
Doğalgaz & $\mathbf{4 2}$ & $\mathbf{1 0 0}$
\end{tabular}

Tablo 7'ye bakıldığında araştırmanın çalışma grubunda yer alan öğrencilerin 42'sinin $(\% 36,28)$ doğal kaynaklara ilişkin metaforlarının, "İklimlendirme-1sıtma-soğutma" kategorisinde toplandığı görülmektedir. Bu kategoride cevapların, katılımcıların bulunduğu yerleşim bölgelerine 
göre değiştiği dikkat çekmektedir. Bu kategori altındaki metaforlar başlıca, "Soba" $(\% 38,09)$, "Klima" (\%19,04), "Fırın" (\%19,04) ve "Saç kurutma makinesi" (\%9,52) şeklinde sıralanmıştır. Fakat bu metafor kategorisini diğerlerinden ayıran temel özelliğin frekanslarından ziyade cevapların öğrencilerin bulunduğu yerleşim yerlerine göre keskin bir şekilde ayrılması olduğu göze çarpmaktadır. Soba cevabı veren 16 öğrencilerden 11'inin köyde, 4'ünün de kasabada yaşadığı tespit edilmiştir. Buna karşılık klima cevab1 veren 8 öğrencinin ve kalorifer cevabı veren 2 öğrencinin tamamının il merkezinde yaşadığı görülmektedir. Bu verilere göre öğrencilerin doğal kaynak kavramına ilişkin ürettiği metaforlarda yakın çevresinde gördüğü nesnelerden etkilendiği görülmektedir. Ayrıca öğrencilerin yaşadığı yerleşim yerine ait sosyo-ekonomik yapının da ürettikleri metaforlarda önemli rol oynadığı dikkat çekmektedir. Bu değerlendirmeyi destekleyen bazı öğrenci görüşleri şu şekildedir:

"Doğal kaynaklar sobaya benzer. Güneş, sobanın görevini kullanarak bizi ısıtır. Güneş aynı zaman da yolumuzu aydınlatır."

"Doğal kaynaklar klimaya benzer. Yazın bizi serinletir ve bunalmamamızı sağlar."

"Doğal kaynaklar kalorifere benzer. Hava soğuyunca bizi ısıtır."

"Doğal kaynaklar firın gibidir çünkü bizi ısıtır."

Tablo 8: Hayatın Devamlılığı

\begin{tabular}{ccc}
\hline Metafor & $\mathbf{f}$ & $\mathbf{\%}$ \\
\hline Hayat & 1 & 12,50 \\
Yaşam & 1 & 12,50 \\
Ömür & 1 & 12,50 \\
Organlar & 1 & 12,50 \\
Hediye & 2 & 25 \\
Mucize & 2 & 25 \\
\hline Toplam & $\mathbf{8}$ & $\mathbf{1 0 0}$ \\
\hline
\end{tabular}

Tablo 8 incelendiğinde araştırmanın çalışma grubunda yer alan öğrencilerin 8 'inin $(\% 8,62)$ doğal kaynaklara ilişkin metaforlarının, "Hayatın devamlılığı" kategorisinde toplandığı görülmektedir.

Bu kategori altındaki metaforların dengeli dağıldığı fark edilmektedir. Ayrıca öğrencilerin ürettikleri metaforlardan yola çıkarak doğal kaynaklara yaşamsal önem atfettikleri değerlendirmesi yapılabilir. Bu değerlendirmeyi destekleyen öğrenci görüşleri şu şekildedir:

"Doğal kaynaklar bir ömre benzer. Onlar olmazsa yaşayamayız." yararlanırız."

"Doğal kaynaklar yaşama benzer. Yaşamımızın her yerinde doğal kaynaklardan

"Doğal kaynaklar mucize gibidir. İnsan hayatına etkisi paha biçilemez." ettiremez."

"Doğal kaynaklar organlarımız gibidir çünkü onlar olmadan insan hayatını devam 


\begin{tabular}{ccc}
\multicolumn{3}{c}{ Tablo 9: İhtiyaçları Karşılama } \\
\hline Metafor & $\mathbf{f}$ & $\mathbf{\%}$ \\
\hline Manav & 1 & 6,81 \\
Anne & 3 & 25,00 \\
Baba & 1 & 6,81 \\
Saklama kabı & 1 & 6,81 \\
Öğretmen & 1 & 6,81 \\
Doktor & 1 & 6,81 \\
Yardımcı alet & 1 & 6,81 \\
Pizza & 1 & 6,81 \\
Pasta & 1 & 6,81 \\
Değer & 1 & 6,81 \\
\hline Toplam & $\mathbf{1 2}$ & $\mathbf{1 0 0}$
\end{tabular}

Tablo 9'a bakıldığında araştırmanın çalışma grubunda yer alan öğrencilerin 12'sinin $(\% 10,34)$ doğal kaynaklara ilişkin metaforlarının, "İhtiyaçları karşılama” kategorisinde toplandığı görülmektedir.

$\mathrm{Bu}$ kategoriye göre doğal kaynakların öğrenciler için birincil gördüğ ü ihtiyaç ve isteklerini çağrıştırdığı sonucuna ulaşılabilir. Ulaşılan bu sonuca katkı sunan öğrenci görüşleri şu şekildedir: kolaylaştırır."

"Doğal kaynaklar hediyeye benzer çünkü bize yardım eder. Hediyeler de bizim işimizi

"Doğal kaynaklar saklama kabına benzer. İçinde insan ve güzellikleri barındırır."

"Doğal kaynaklar yardımcı aletlere benzer. Bunlar olmasaydı hayatımızda eksiklikler olurdu. Doğal kaynaklar insan hayatının bir parçasıdır."

"Doğal kaynaklar elimizde olup değerini bilemediğimiz şeylere benzer. Değerini bilemediğimiz şeyleri boş yere harcarız. Değerini geç anlarız."

\section{Sonuç ve Tartışma}

Ortaokul öğrencileri tarafından üretilen 38 metafor toplam 5 kategori altında toplanmıştır. Bunlar sırasıyla; İklimlendirme-1sıtma-soğutma (\%36,28), Tükenmeme-yenilenebilir olma (\%25), Işık-Aydınlatma $(\% 19,82)$, İhtiyaçları karşılama $(\% 10,34)$ ve Hayatın devamlılı̆̆ $(\% 8,62)$ şeklinde sıralanmaktadır. Bununla birlikte kategori bağlamının dışında metafor olarak verilere bakılacak olursa, ortaokul öğrencileri tarafindan üretilen metaforlardan en s1k tekrar edilenler; Soba (\%8), Tükenmez kalem $(\% 3,3)$, Lamba $(\% 3)$, Işık $(\% 2,7)$, Fırın $(\% 2,1)$, Klima $(\% 2,1)$ ve Güneş $(1,8)$ şeklinde sıralanmıştır. Bu çalışmada elde edilen sonuçların, farklı kavramları açıklamak için yapılmış birçok araştırmanın sonuçları tarafından desteklendiği görülmüştür. Öğrencilerin ürettiği metaforlar göz önüne alındığında doğal kaynakları yakın çevrelerindeki somut nesnelere ve kavramlara benzetme eğiliminde oldukları görülmüsşür. Katılımcıların doğal kaynaklar kavramına bakış açılarının okullarının bulunduğu yerleşim yerine göre de değiştiği görülmüştür. Öğrencilerin doğal kaynak kavramına ilişkin ürettikleri metaforların yakın çevresindeki varlıklara benzettikleri tespit edilmiştir. Köyde ve kasabada yaşayan öğrenciler, iklimlendirme-1sitma-soğutma kategorisinde doğal kaynakları ağırlıklı olarak sobaya benzetirken, şehir merkezinde öğrenim gören ve ikamet eden öğrenciler ise bu kategoride daha çok klima ve kalorifer metaforu üretmişlerdir. Doğan (2017) çalışmasında ortaokul öğrencilerinin çevre kavramına ilişkin metaforik algılarının daha çok öğrenim deneyimlerine ve yaşantıları sonucu elde ettikleri tecrübelere dayandığını ifade etmektedir. Shepardson (2005), çocukların çevreye karşı tutumlarını incelediği çalışmasında, çocukların çevreyi ihtiyaçlarını karşıladıkları ve yaşamlarını sürdükleri bir yer olarak gördüklerini belirtmektedir. Ateş ve Karatepe (2013) ve Çakmak (2015) çalışmalarında üniversite öğrencilerinin ve öğretmen adaylarının çevreye ilişkin metaforik algılarının ihtiyaçlar çerçevesinde olduğunu belirtmişlerdir. 
Araştırmanın bir diğer bulgusunda ise ortaokul 6. ve 7. sınıf öğrencilerinin doğal kaynaklar kavramını hayatın devamı çerçevesinde değerlendirdikleri görülmektedir. Çakmak (2018) çalışmasında Türkiye'de çevre ve doğa kavramlarıyla ilgili yapılan çalışmalarda en çok üretilen metaforların hayat, evimiz, nefes ve canlı olduğunu belirtmiştir. Vining, Merrick ve Price (2008) çalışmalarında öğrenciler doğayı insan eli değmemiş, bakir olarak betimlemişlerdir. Bunun yanı sıra katılımcılar doğal kaynakları genel olarak oluşum özelliklerine göre değerlendirmedikleri görülmüștür. Öğrenciler çoğunlukla doğal kaynakları nihai kullanım alanlarına göre sınıflandırmakta ve algılamaktadır. Bununla birlikte öğrencilerin doğal kaynakları sosyal bilgiler dersi müfredatı doğrultusunda yenilenebilir olup olmama özelliğine göre algıladıkları tespit edilmiştir. Bu noktada sosyal bilgiler dersinde kavram öğretiminin önemi ortaya çıkmaktadır.

Soyut kavramların yoğunlukla bünyesinde bulunduran sosyal bilgiler öğretiminde kavram öğretimi yöntemlerine ağırlık verilebilir. Bu şekilde öğrencilerin eksik ve yanlış öğrenmelerinin önüne geçilebilir. Bundan sonra yapılacak çalışmalarda çalışma grubuna; sosyal bilgiler öğretmenleri, sosyal bilgiler öğretmen adayları, çeşitli türdeki lise öğrencileri, okul yöneticileri ve veliler de dahil edilebilir. Doğal kaynaklar-metafor bağlamında yapılmış çalışmaların bulguları ışığında farklı veri toplama araçları geliştirilebilir. Doğal kaynaklar bağlamında kavramlar arasında öğrencilerin bağlantı kurmasını sağlayacak öğretim yöntemleri okullarda uygulanabilir.

\section{Kaynakça}

Aktaş, E., Uzuner Yurt, S. (2016). Öğrencilerin Türkçe, Arapça ve İngilizceye yönelik algılarının metaforlar aracılığılla belirlenmesi: Erzincan ili örneği. Akın, H. (ed.) Uluslararası Erzincan Sempozyumu bildiri kitabı içinde (347-357). Erzincan Üniversitesi.

Arslan, M. M. ve Bayrakçı, M. (2006). Metaforik düşünme ve öğrenme yaklaşımının eğitim-öğretim açısından incelenmesi. Millî Eğitim, 35(171), 100-108.

Ateş, M ve Karatepe, A. (2013). Üniversite öğrencilerinin "çevre" kavramına ilişkin algılarının metaforlar yardımıyla analizi. The Journal of Academic Social Science Studies, 6(2), 13271348 .

Aydın, İ. S., Pehlivan, A. (2010). Türkçe öğretmeni adaylarının "öğretmen" ve "öğrenci" kavramlarına ilişkin kullandıkları metaforlar. Turkish Studies, 5(3), 818-842.

Batur, Z., Uygun, K., (2012) İki Neslin Bir Kavram Algıs1: Teknoloji. Uşak Üniversitesi Sosyal Bilimler Dergisi, 5 (1), 74-88.

Bayram, B. (2018). Öğretmen adaylarının ana dili eğitimi sürecinde okuma becerilerine ilişkin algılarının metaforlar aracılığıyla belirlenmesi. Turkish Studies, 13(14), 99-116.

Bektaş, M. Okur, A. Karadağ, B. (2014). İlkokul ve ortaokul son sınıf öğrencilerinde metaforik alg1 olarak kitap. Türk Kütüphaneciliği, 28 (2), 154-168.

Bozpolat, E. (2015). Türkçe öğretmen adaylarının dört temel dil becerisine ilişkin metaforik algıları. Turkish Studies, 10(11), 313-340.

Çakmak, M. (2015). Öğretmen adaylarının çevre kavramı metaforik algılarının incelenmesi (Artuklu Üniversitesi örneği). XII. Ulusal Ekoloji Ve Çevre Kongresi özet kitapçı̆̆ında yer alan bildiri, Muğla, Türkiye, 14-17 Eylül.

Çakmak, M. (2018). Türkiye'de çevre kavramı bağlamında yapılan metafor çalışmalarının içerik analizleri. Akdeniz Eğitim Araştırmaları Dergisi, 12(25), 172-193. http://dx.doi.org/10.29329/mjer.2018.153.10 
Doğan, Y. (2017). Ortaokul öğrencilerinin çevre kavramına ilişkin sezgisel algıları: Bir metafor analizi. Ahi Evran Üniversitesi Kırşehir Eğitim Fakültesi Dergisi 18 (1), 721-740.

Doğanay, H. (2002). Doğal Kaynaklar, Aktif Yayınları.

Duban, N. ve Arısoy H. (2017). 8. Sınıf öğrencilerinin temel eğitimden orta öğretime geçiş (TEOG) sınavına ilişkin algılarının metaforlar aracılığıyla incelenmesi. Kalem Eğitim ve İnsan Dergisi, 7 (1), 67-98.

Ekici, G. (2016). Öğretmen adaylarının "bilgisayar” kavramına ilişkin metaforik algıları. Gaziantep University Journal of Social Sciences, 15 (3), 755-781.

Er Tuna, Y. ve Mazman Budak, F. (2013). Sosyal bilgiler öğretmen adaylarının "tarih" kavramına ilişkin algılarının mecazlar/metaforlar yardımıyla analizi. Adıyaman Üniversitesi Sosyal Bilimler Enstitüsü Dergisi, 6 (14), 609-642.

Finlay, L. (2008). A dance between the reduction and reflexivity: Explicating the "Phenomenological psychological attitude". Journal of Phenomenological Psychology, 39 (2008), 1-32.

Güveli, E., İpek A. S., Atasoy E. ve Güveli, H. (2011). Sınıf öğretmeni adaylarının matematik kavramına yönelik metafor algıları. Turkish Journal of Computer and Mathematics Education, 2 (2), 140-159.

İlter, İ. (2015). Primary school teacher candidates' metaphorical perceptions related to multigrade classes concept. Elementary Education Online, 14 (4), 1450-1468.

Kalraa, M, B ve Bavejab, B. (2012) International conference on newhorizons in education inte2012. Procedia - Socialand Behavioral Sciences, 55, 317 - 326.

Kalyoncu, R. (2012). Görsel sanatlar öğretmen adaylarının öğretmenlik kavramına ilişkin metaforları. Mustafa Kemal Üniversitesi Sosyal Bilimler Dergisi, Sayı. 20, 471-484.

Karakuş, N., Kozçetin, K. (2016). Türkçe öğretmeni adaylarının okuma kavramına yönelik metaforik algılarının incelenmesi. Mehmet Akif Ersoy Üniversitesi Eğitim Fakültesi Dergisi, S.40, $387-$ 404.

Lakoff, G. ve Johnson, M. (2005). Metaforlar: Hayat, anlam ve dil (Çev. G. Y. Demir). Paradigma.

Levine, P. M. (2005). Metaphors and Images of Classrooms, Kappa delta Pi Record, 4, 41 (4), 172175.

Lin, W. C., Shein, P. P ve Yang, S. C. (2012). Exploring persona lefl teaching metaphors in preservice teachereducation. English Teaching: Practice and Critique, 11(1), 183-199.

Lüle Mert, E. (2013). Türkçe öğretmen adaylarının dört temel dil becerisine ilişkin algılarının metaforlar aracılığıyla analizi. Uluslararası Sosyal Araştırmalar Dergisi, 6 (27), 357-372.

Michael, K ve Malamitsa, K. (2009). Exploring greek teachers belief susing metaphors. Australian Journal of Teacher Education, 34 (2), 64-83.

Miles, M. B. and Huberman, A. M. (1994). Qualitative data analysis: an expanded sourcebook. (2. bask1). SAGE Publications.

Morgan G. (1998). Yönetim ve örgüt teorilerinde metafor. Mess Yayınları.

Mouraz, A., Pereira, A. V ve Monteiro, R. (2013). The use of metaphors in the processes of teaching and learning in higher education. International Online Journal of Educational Sciences, 5 (1), 99-110. 
Ocak, G. ve Gündüz, M. (2006). Eğitim fakültesini yeni kazanan öğretmen adaylarının öğretmenlik mesleğine giriş dersini almadan önce ve aldıktan sonra öğretmenlik mesleği hakkındaki metaforlarının karşılaştırılması. Afyon Kocatepe Üniversitesi Sosyal Bilimler Dergisi, 8 (2), 293-309.

Özdemir, T. Y., Erol, Y. C. (2015). Pedagojik formasyon eğitimi alan öğretmen adaylarının okul, öğretmenlik ve öğrenci kavramlarına ilişkin algıları. Celal Bayar Üniversitesi Sosyal Bilimler Dergisi, 13(4), 215-244.

Patton, M. Q. (2002). Qualitative evaluation and research methods (3. bask1). Sage Publications, Inc.

Saban, A. (2008). “İlköğretim I. Kademe Öğretmen ve Öğrencilerinin Bilgi Kavramına İlişkin Sahip Oldukları Zihinsel İmgeler”. İlkögrretim Online, 7 (2), 421-455.

Saban, A., Koçbeker, B. N. ve Saban, A. (2006). Öğretmen adaylarının öğretmen kavramına ilişkin algılarının metafor analizi yoluyla incelenmesi. Kuram ve Uygulamada Eğitim Bilimleri, 6, 461-522.

Shaw, D., Massengill, B ve Mahlios, M. (2008). Preservice teachers' metaphors of teaching in relation to literacy beliefs. Teachers and Teaching: Theory and Practice, 14 (1), 35-50

Shepardson, D.P. (2005). Student ideas: What is an environment. Journal of Environmental Education, 36(4), 49-58.

Tiryaki, E. N, Demir, A. (2016). Türkçe öğretmeni adaylarının yazma becerisine yönelik metaforik algıları. Mustafa Kemal Üniversitesi Sosyal Bilimler Enstitüsü Dergisi, 13 (33), 18-27.

Uğurlu, N. B. (2007). Sosyal bilgiler dersinde "Türkiye’nin doğal kaynakları” Konusunun coğrafi bilgi sistemleri ile öğretiminin öğrencilerin tutum ve başarısına etkisi. Yayınlanmamış doktora tezi. Gazi Üniversitesi Eğitim Bilimleri Enstitüsü.

Uygun, K. (2018). Sosyal Bilgiler Programı ve Yapılandırmacılık. (Ed: Çalışkan, H; Kılcan, B.) Sosyal Bilgiler Öğretimi. (s.53-86), Lisans Yayıncılık.

Uygun, K., Batur, Z. (2015). Öğretmen Adaylarının Sosyal Bilgiler Öğretiminde Kullanılan Kavramlara İlişkin Algıları. International Journal of Social and Educational Sciences (IJOSES), 2 (4), 127-147.

Vining, J, Merrick, M.S. ve Price E.A. (2008) The Distinction between Humans and Nature: Human Perceptions of Connectedness to Nature and Elements of the Natural and Unnatural, Human Ecology Review, 15(1), 1-11

Yıldırım, A. ve Şimşek, H. (2005). Sosyal bilimlerde nitel araştırma yöntemleri. Seçkin Yayınevi.

Yılmaz, F., Göçen, S., Yılmaz, F. (2013). Öğretmen adaylarının öğretmen kavramına ilişkin algıları: Bir metaforik çalışma. Mersin Üniversitesi Eğitim Fakültesi Dergisi, 9 (1), 151-164.

Zhang, X. (2016). Examining english language teachers through metaphorical analysis. Theory and Practice in Language Studies, 6 (8), 1659-1664. 